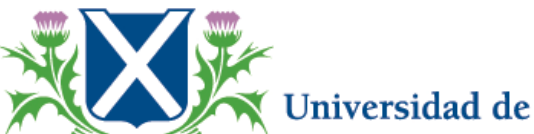 SanAndrés
}

\section{When You Can't Tube... Impact of a Major Youtube Outage on Rapes}

Por María Amelia Gibbons (Universidad de San Andrés \& University of Wisconsin-Madison) y Martín Rossi (Universidad de San Andrés)

D.T.: $\mathbf{N}^{0} 133$

Abril 2020

Vito Dumas 284, B1644BID, Victoria, San Fernando, Buenos Aires, Argentina Teléfono 4725-7020, Fax 4725-7010

Email: economia@udesa.edu.ar 


\title{
When You Can't Tube... Impact of a Major YouTube Outage on Rapes*
}

\author{
M. Amelia Gibbons \\ University of Wisconsin-Madison \\ Universidad de San Andrés
}

\author{
Martín A. Rossi \\ Universidad de San Andrés
}

\begin{abstract}
On Tuesday, October $16^{\text {th }}, 2018$, YouTube experienced a major and rare global service outage. Using high-frequency crime data from the U.S., we document an important increase in rapes in the 24-hour period following the outage. We then investigate various potential underlying channels that may link the YouTube outage to the subsequent observed increase in rapes. We explore a direct effect on crime, time substitution, an effect on drug and alcohol-related offenses, and the increase in pornography viewing, and the overall evidence only supports the hypothesis that the increase in rapes was driven by an increase in pornography viewing.
\end{abstract}

Keywords: Sexual crime, sexual offenses, event study, social media, pornography.

JEL classification: K42.

\footnotetext{
* Maria Amelia Gibbons (mgibbons3@wisc.edu), Department of Agricultural and Applied Economics \& Center for Demography and Ecology, University of Wisconsin-Madison and Department of Economics, Universidad de San Andrés; Martín A. Rossi (mrossi@udesa.edu.ar), Department of Economics, Universidad de San Andrés, Vito Dumas 284, B1644BID Victoria, Buenos Aires, Argentina. We acknowledge invaluable help from Junaid Khalid in the construction of the dataset. We thank Bradford Barham, Santiago Barraza, Tommy Murphy, Jenna Nobles, Juan Pedro Ronconi, and Laura Schechter for useful comments and suggestions. Seminar audiences in University of San Francisco, AAEA Annual Meeting, Universidad de San Andrés, Argentine Economic Association, Association for Public Policy Analysis and Management, Bay Area Behavioral and Experimental Economics Workshop, and University of Wisconsin-Madison provided very helpful feedback.
} 


\section{Introduction}

Social media is an important part of many people's lives. Nowadays, an average adult spends approximately 54 minutes a day consuming social media. ${ }^{1}$ Among the many social media sites available, YouTube is the most widely used site by adults in the United States. According to a nationally representative survey conducted in January 2019, 73\% of American adults use YouTube regularly, and 51\% of YouTube users say they visit the site daily. ${ }^{2}$

The increase in the use of social media raised an important debate in the public sphere on the potential effects of social media exposure on economic and social outcomes. Our paper contributes to this debate by studying the short-run effects of deprivation of consumption of social media. In particular, we study the impact of a major YouTube outage on subsequent rapes. On Tuesday, October $16^{\text {th }}, 2018$, between $9 \mathrm{pm}$ and $11 \mathrm{pm}$ Eastern time, YouTube experienced a major and rare global service outage. Using high-frequency data on reported criminal incidents from the U.S. for the period January $1^{\text {st }}, 2017$ to April $1^{\text {st }}, 2019$, we document an important increase in rapes in the 24-hour period following the outage. Our results are robust to controlling for day of the week dummies, day of the month dummies, month dummies, different specifications of a time trend, and a set of weather variables (precipitations, temperature, snowfall). Results are also robust to alternative time windows ( 820 days, 91 days, 61 days, 31 days), inference strategies (Newey-West, randomized inference, clustering), model specifications (ordinary least squares, negative binomial model for count data), and type of data (time series, panel structure).

We then investigate potential underlying channels or mechanisms that may link the YouTube outage to the subsequent observed increase in rapes. We find that other

\footnotetext{
${ }^{1}$ Millennials spend approximately 114 minutes a day. Retrieved from http://www.thevab.com/wpcontent/uploads/2017/, on May $7^{\text {th }}, 2019$.

${ }^{2}$ Retrieved on April 1 $10^{\text {th }}, 2019$, from https://www.pewresearch.org/fact-tank/2019/04/10/.
} 
crimes and offenses (including drug, alcohol, and other sexual offenses) were not affected by the outage. We also report that the observed increase in rapes did not occur in the 2-hour period during the outage, but in the 22-hour period after YouTube service has been restored. Finally, we document that in the 2-hour period during YouTube's disruption there was an important increase in traffic on the online adult video site Pornhub (the world's biggest pornography site), which implied millions of additional viewers during Pornhub's peak hours. Overall, these findings suggest that the observed link between YouTube outage and rapes may be operating through the increase in pornography viewing.

There is an important literature on the drivers of sexual aggression, as well as on the characteristics of sexual crime perpetrators and their modus operandi. ${ }^{3}$ According to this literature, most rapes are committed by relatives or acquaintances of the victim (Russell 1984; Koss et al. 1988; National Research Council 1996; Gavey 2013). ${ }^{4}$ We do not have information about who was the perpetrator, so we are unable to analyze this point. Though being related to this general literature, our paper is not on the causes of rapes, but on the causal effect of deprivation of a social media on rapes. As such, our research only explains a relatively small fraction of rapes.

Our paper is related to the literature on the impact of media on many outcomes, such as education, family choices, labor and migration decisions, environmental choices, health, crime, attitudes, consumption and savings, and financial choices (for a review of this literature -mainly radio and television-, see DellaVigna and La Ferrara 2015). There is also a small literature on the effects of social media (Enikolopov,

\footnotetext{
${ }^{3}$ Groth (1979) identified a least four types of rapists: opportunist rapists (30\%) who exhibit no anger toward the women they assault and usually use little or no force; anger rapists $(40 \%)$ who batter the survivor and use more physical force than is necessary to overpower her; power rapists $(25 \%)$ who do not intend to physically harm their victim but rather to possess or control her to gain sexual gratification; and sadistic rapists (5\%) who become sexually excited by inflicting pain on their victim.

4 According to RAINN, 8 out of 10 rapes are committed by someone known to the victim (https://rainn.org/statistics/perpetrators-sexual-violence).
} 
Petrova, and Sonin 2018; Enikolopov, Makarin, and Petrova 2017) and a recent experimental research that focuses on how people react to deprivations to the consumption of social media (Mosquera et al. 2018; Allcott et al. 2019). ${ }^{5}$

Our finding that pornography viewing can lead to an increase in rapes adds to a long-standing debate in the U.S. regarding the effects of pornography. As far back as in 1968, President Lyndon B. Johnson sets up the President's Commission on Obscenity and Pornography to study the effects of pornography on crime and on other antisocial conducts. The Commission concluded there was insufficient evidence to link the exposure to pornography to subsequent aggression, particularly in sexual crime. The report triggered an important amount of research (mainly in the fields of criminology, experimental psychology, and sociology) on the effects of pornography on sexual aggression. Ferguson and Hartley (2009) provide a review of this research and, in line with the report, conclude that pornography is not associated with increased sexual assault behavior. However, some authors have challenged these findings, providing evidence that pornography is associated with an increase in violent sexual behavior. Malamuth, Addison, and Koss (2000) provide a review of this literature and conclude that the evidence supports the existence of a positive association between frequent use of pornography and sexually coercive behavior, particularly for men at high risk for sexual aggression. ${ }^{6}$ Additionally, the literature that analyzes sexual offenders' modus operandi documents that most sexual offenders use pornography to feed their deviant and violent fantasies (see Johnson 2006).

Given that most of the evidence available on the impact of pornography on rapes comes from correlational studies, it is difficult to interpret this evidence in a causal

\footnotetext{
5 There is also some research in economics that studies the impact of internet availability and sexual crime (Bhuller et al. 2013; Nolte 2019).

${ }^{6}$ For a more recent review of the literature showing a positive link between pornography and rapes, see Foubert (2017).
} 
way. The experimental research available focuses on hypothetical behavior in the lab, and the experimental subjects are mainly college students (Malamuth and Ceniti 1986; Linz, Donnerstein, and Penrod 1988; Fisher and Grenier 1994; Hald and Malamuth 2005; Yang, Dong-ouk, and Gahyun Youn 2012). ${ }^{7}$ Thus, the question of whether pornography actually increases or reduces rapes is still open. Our paper provides evidence that supports the hypothesis that an increase in pornography viewing may lead to an increase in rapes.

Finally, our paper contributes to the literature on criminal decision-making. The rational choice theory postulates that rational agents decide whether to engage in criminal activities by comparing the benefits and costs of committing a crime (Becker 1968). A recent literature shows that emotional cues or visceral factors (i.e., frustration and euphoria) also affect crime decisions, such as the decisions to engage in domestic violence (Card and Dahl 2011), violent crime (Munyo and Rossi 2013), and sexual crime (Lindo, Siminski, and Swensen 2018). In line with this literature, our results suggest that a fraction of sexual crime can be better characterized as a breakdown of control rather than a behavior driven by rational choice.

The organization of the paper is as follows. Section II presents the natural experiment and describes the data. Section III presents the empirical strategy and reports the results. Section IV explores mechanisms. Section V provides a simple theoretical framework to rationalize our findings Section VI concludes.

\section{Natural experiment and data}

YouTube experienced a major and rare global service outage on October $16^{\text {th }}$, 2018, between 9pm and $11 \mathrm{pm}$ Eastern time. Users who tried to access the website during this period were greeted with a blank page that showed no videos. On the app,

\footnotetext{
${ }^{7}$ There is also literature discussing the limitations of this type of studies (Mould 1988; Jensen 1995).
} 
an error message read which said 'There was a problem with the network [503].' According to Downdetector, the first massive reports $(13,650)$ were found at 9:01:11 pm, Eastern time.

The outage received extensive coverage in the media. ${ }^{8}$ Figure 1 displays the evolution of daily reported problems in the YouTube site for the period May 2017 to February 2019. We obtain YouTube reports data from Downdetector, who collects status reports from a series of sources (such as Twitter). Through a real-time analysis of this data, Downdetector automatically detects outages and service interruptions at a very early stage. An outage exists when the number of reports shows a significant jump relative to the baseline. As observed in Figure 1, there is a clear and unusual spike in reported problems on October $16^{\text {th }}, 2018 .^{9}$

We use high-frequency (hourly) data on reported criminal incidents in the U.S. for the period January $1^{\text {st }}, 2017$, to April $1^{\text {st }}, 2019$. These data were collected by Socrata. ${ }^{10}$ The Socrata dataset aggregates all reported incidents at 295 police departments and sheriffs' offices (from a total of 17,784 police departments and sheriffs' offices in the U.S.), and represents $6.4 \%$ of the U.S. population.

From the original hourly data, we generate a "daily" dataset that uses the date and time of the reported incident, so that all "days" start at the time of the outage (9pm Eastern time). For example, in the new dataset October $1^{\text {st }}$ corresponds to the 24-hour period that starts at $9 \mathrm{pm}$ Eastern time on October $1^{\text {st }}$ and ends up at $8.59 \mathrm{pm}$ Eastern time on October $2^{\text {nd }}$. In this way, we end up with 820 "daily" observations.

\footnotetext{
${ }^{8}$ See, for example, www.msn.com/en-gb/money/technology/googles-youtube-suffers-a-major-outage/; www.cnbc.com/2018/10/17/googles-youtube-outage-affected-users-in-us-australia-asia-europe.html; www.usatoday.com/story/tech/talkingtech/2018/10/16/youtube-offline-worldwide-social-mediainternet/.

${ }^{9}$ Other minor outages were on June $16^{\text {th }}, 2017$ at 10 am for less than an hour; November $12^{\text {th }}, 2018$ at $5 \mathrm{pm}$ for an hour; November $18^{\text {th }}, 2018$ at $7 \mathrm{pm}$ for half an hour.

${ }^{10}$ Socrata provides a data-as-a-service platform bringing together existing government data. Datasets downloaded on April 21 ${ }^{\text {st }}, 2019$ from https://moto.data.socrata.com/browse?limitTo=datasets (not currently available, see capture at web.archive.org/web/20191013052124/https:/moto.data.socrata.com).
} 
We define an incident as a rape if the record has the word "rape" or the corresponding police code in the primary incident type column or in the incident description. ${ }^{11}$ In our sample, there is an average of 6.5 rapes per day. ${ }^{12}$

The dataset also includes other criminal and non-criminal offenses. Among them, we collected data on the most frequently reported crimes and offenses, which together account for approximately $80 \%$ of the total number of reports. These are traffic offenses, community policing, disorder, theft (includes theft from vehicle, theft of a vehicle, robberies, property crime, and breaking \& entering), and assault. Among these categories, we group theft and assault as criminal offenses, and traffic offenses, community policing, and disorder as non-criminal offenses. Additionally, we create variables on drug and alcohol-related offenses by aggregating all offenses that include the word "drug" and "liquor" in the incident description, respectively. Table 1 reports the summary statistics of the data.

\section{Empirical strategy and results}

We are interested in estimating the impact of YouTube outage on rapes during the 24 hours following the outage. Formally, we estimate the following equation:

$$
\text { Rapes }_{t}=\alpha+\beta \text { YouTube outage } t+\varphi X_{t}+\varepsilon_{t}
$$

where Rapest is the total number of rapes on day $t$, YouTube outage $t$ is a dummy variable that takes the value one from October $16^{\text {th }}, 2018,9 \mathrm{pm}$ to October $17^{\text {th }}, 2018$, $8.59 \mathrm{pm}$ Eastern time, and zero otherwise, $\beta$ is the parameter of interest, and $\varepsilon_{t}$ is the error term. Depending on the particular specification, the set of controls $\left(X_{t}\right)$ includes day of the week dummies (7), month dummies (12), day of the month dummies (31), and a linear time trend ( 1 to 820$)$.

\footnotetext{
${ }^{11}$ A police code is a numerical brevity code for a crime, incident, or instructions for police officers. https://en.wikipedia.org/wiki/Police_code and https://web.stanford.edu/ reneeb/bill/n.radio.code.html.

${ }^{12} 66 \%$ of the police stations do not report any rapes in our sample.
} 
We estimate equation (1) using Ordinary Least Squares (OLS). We deal with potential heteroskedasticity and serial correlation by conducting inference on the parameter of interest in three alternative ways. First, we report White-Huber robust standard errors. Second, we report Newey-West heteroskedasticity- and autocorrelation-consistent standard errors. ${ }^{13}$ Third, we conduct randomized inference and report p-values obtained from permutation tests on the basis of Monte Carlo simulations, using the ritest command in Stata (Heß 2017).

In column (1) of table 2, we report estimates of equation (1) without controls. The coefficient on YouTube outage is positive and statistically significant at the usual levels of confidence. The value of the coefficient implies a 1.4 standard deviation increase in rapes in the 24-hour period following the outage. In columns (2) to (5) in table 2 we show that results are robust to controlling for day of the week dummies, month dummies, day of the month dummies, and a linear time trend. ${ }^{14}$

Table 3 reports results for alternative time windows. We consider three symmetric periods around October $16^{\text {th }}, 2018$ : September $1^{\text {st }}$ to November $30^{\text {th }}(91$ days), September $16^{\text {th }}$ to November $15^{\text {th }}$ (61 days), and October $1^{\text {st }}$ to October $31^{\text {st }}(31$ days). In all cases, the coefficient on YouTube outage is positive and statistically significant, with estimated values in a similar range as the ones reported in table 2.

Table 4 reports results obtained from restricting the sample to the 24-hour period starting on Tuesdays at 9pm Eastern time. There are 117 "Tuesdays" in our sample. Again, the coefficient for YouTube outage is positive and statistically significant, with estimated values that imply an increase in rapes in the range of 1.6 to 2.8 standard

\footnotetext{
${ }^{13}$ In all cases, the heuristic applied to obtain the number of lags is taken from the first step of Newey and West's (1994) plug-in procedure that sets the number of lags as floor $\left[4(\mathrm{~T} / 100)^{2 / 9}\right]$, where $\mathrm{T}$ is the number of observations.

${ }^{14}$ We obtain similar results when we include a non-linear trend, or when instead of the trend we include month-year combination dummies.
} 
deviations, ${ }^{15}$ depending on the particular specification. Figure 2 plots the distribution of rapes in the 117 Tuesdays in our sample, and shows that only $3.42 \%$ of Tuesdays have more reported rapes than October $16^{\text {th }}, 2018 .^{16}$

To alleviate potential concerns arising from the use of a linear probability model when the outcome is discrete, as further robustness check we reproduce previous results using a regression model for discrete count outcomes. Panels A, B, and C in table 5 reproduce tables 2,3 , and 4, respectively, using a negative binomial specification. Overall, estimates in table 5 indicate that our main conclusions are robust to using count models.

\section{$\underline{\text { Panel structure }}$}

Aggregation gives rise to potential concerns about bias due, for example, to inconsistent reporting of police departments throughout the sample (after all, rape is one of the noisier crime measures due to under-reporting). Therefore, to further validate our results, we exploit police-station level data.

Using police-station level data allow us to introduce additional controls that vary by time and police station. First, we include a set of police-station specific trends. Second, we control for weather conditions. This is potentially important since there is an extensive literature that examines the link between weather conditions (specifically temperature and precipitation) and the occurrence of rape (see DeFronzo1984; Perry and Simpson 1987; Cohn 1993).

The panel database has 295 police stations and 820 days, with a total of 241,900 observations. In this database, the mean of Rapes is equal to 0.022 , with a standard deviation equal to 0.232 .

Formally, we estimate the following equation:

\footnotetext{
15 The standard deviation of Rapes in the sample of Tuesdays is equal to 2.75 .

16 These Tuesdays are 08/22/2017, 05/15/2018, 06/12/2018, and 07/10/2018.
} 


$$
\text { Rapes }_{i t}=\alpha_{i}+\beta \text { YouTube outage } \text { it }+\varphi X_{t}+\pi H_{i t}+\varepsilon_{i t}
$$

where Rapes $_{i t}$ is the total number of rapes in police station $i$ on day $t, \alpha_{i}$ is a policestation fixed effect, YouTube outage $e_{i t}$ is a dummy variable that takes the value one for police station $i$ from October $16^{\text {th }}, 2018,9 \mathrm{pm}$ to October $17^{\text {th }}, 2018,8.59 \mathrm{pm}$ Eastern time, $\beta$ is the parameter of interest, and $\varepsilon_{i t}$ is the error term. Depending on the specification, $X_{t}$ includes day of the week dummies and month dummies, and $H_{i t}$ includes maximum temperature, minimum temperature, precipitations, snowfall, and a set of police-station specific trends. In all cases, we report standard errors clustered at police station and day level.

Column (1) in table 6 reports the specification without controls. The coefficient for YouTube outage is positive and significantly different from zero, and its value implies an average increase of 0.017 rapes per police station (out of an average value equal to 0.022 ). As shown in columns (2) to (4), the point estimator is robust to the inclusion of the set of police-station trends, and to controlling for day of the week dummies and weather conditions. When we additionally control for month dummies (column (5)), the estimated coefficient is similar in magnitude, but rather imprecise.

\section{Further results}

We now investigate various potential underlying mechanisms that may link the YouTube outage to the subsequent observed increase in rapes. We explore: (i) direct effect of the outage on other crimes and offenses, (ii) effect on drug and alcoholrelated offenses, (iii) time substitution, and (iv) pornography viewing.

We first analyze the effect of the outage on criminal offenses (theft, assault, property crime, theft from vehicle, breaking \& entering, and theft of vehicle) and noncriminal offenses (traffic offenses, disorder, community policing, and vehicle stop). As mentioned before, frustration, for instance, could be an emotional cue expressing from 
the unexpected outage, and this could have led to an increase in crime. As shown in columns (1) and (2) in table 7, however, there is no significant association between YouTube outage and criminal and non-criminal offenses. We also explore the effect of the outage on other sexual crimes. As reported in column (3) in table 7, the estimated coefficient is small and statistically not significant, suggesting no effect of the outage on other sexual offenses.

We then investigate the effect of the outage on drug and alcohol-related offenses. This is potentially important since approximately one-half of sexual assaults involve alcohol consumption by the perpetrator, victim, or both (Abbey et al. 2001). Columns (4) and (5) in table 7 show the outage is not significantly related to an increase in drug offenses nor to an increase in alcohol-related offenses.

Overall, results reported in table 7 suggest there is no direct effect of the outage on other crimes and offenses.

A plausible hypothesis is that watching YouTube and committing rape are substitutes. This may arise, for example, if some individuals that were not able to access YouTube get bored and react by committing rape. ${ }^{17} \mathrm{We}$ name this hypothesis as the time-substitution channel. An observational implication of the time-substitution channel is that we should observe an increase in rapes during the outage (that is, in the 2-hour period starting at $9 \mathrm{pm}$ Eastern time on Tuesday $\left.16^{\text {th }}, 2018\right)$. To explore this potential channel we construct an hourly dataset for the period January $1^{\text {st }}, 2017$ to March 31 $31^{\text {st }}, 2019$ (19,680 hours). An anticipation of time-substitution results is reported in figure 3, which shows there is no increase in rapes during the outage, and all the observed increase occurs after the service was restored. To formally test the

\footnotetext{
${ }^{17}$ The literature on sexual offender's modus operandi discusses about several offender's typologies. For example, an offender who is trolling for victims may choose to acquire an opportunistic victim at a location with increased victim availability and vulnerability. Thus, the opportunistic offenders may rape the first person they see (Johnson 2006; Turvey 2013).
} 
time-substitution channel, we generate two new variables. During outage is a dummy variable that takes value 1 in the 2-hour period from $9 \mathrm{pm}$ to $10.59 \mathrm{pm}$ Eastern time on Tuesday $16^{\text {th }}, 2018$. After outage is a dummy variable that takes value 1 in the 22 -hour period starting at $11 \mathrm{pm}$ Eastern time on Tuesday $16^{\text {th }}, 2018$. As reported in table 8 , all the observed effect comes from rapes in the 22-hour period after the outage. Indeed, rapes fell during the outage. These findings do not support the time-substitution channel.

Finally, we explore the pornography-viewing channel. During YouTube's disruption, there was an important increase in traffic on the online adult video site Pornhub, the world's biggest pornography site. The top panel of figure 4 displays hourly data on YouTube reported problems. The bottom panel of figure 4 displays hourly data on Pornhub's traffic from noon Eastern time October $16^{\text {th }}, 2018$, until $2 \mathrm{am}$ Eastern time October $17^{\text {th }}, 2018$. The Pornhub site saw a surge in traffic during YouTube's outage: traffic increased to 12 percent above average at around 9pm Eastern time, when the outage was reported, climbing to 21 percent increase over average traffic one hour later. According to information provided by Pornhub, this increase in traffic implies millions of additional viewers during Pornhub's peak hours. Traffic dropped rapidly once YouTube's service was restored, dropping to slightly below average numbers around midnight Eastern time. ${ }^{18}$

If YouTube viewers were switching to Pornhub during the outage, there must be some substitutability between these two sites. What were YouTube users viewing before the outage? What happened to Pornhub searches during the outage? According to information provided by Pornhub, ASMR (Autonomous Sensory Meridian

\footnotetext{
${ }^{18}$ Using hourly data on YouTube reported problems and Pornhub traffic for the 15-hour window around the outage (from noon October $16^{\text {th }}$ until 2 am October $17^{\text {th }}$, Eastern time), we run a regression of Pornhub's traffic on YouTube reported problems. As expected, the estimated coefficient is positive and highly significant (the estimated coefficient is 0.11 , with a standard error of 0.01 ), indicating that the outage is highly correlated with pornography viewing.
} 
Response) was the word with the highest search growth during YouTube outage: ${ }^{19}$ ASMR searches in Pornhub increased by $201 \%$ compared to the October $16^{\text {th }}, 2018$, hourly average. In Pornhub, searching for ASMR leads to hardcore material that combines the sound effects of ASMR with explicit sexual content. Even though we do not have information on YouTube searches around the outage, there is evidence that ASMR searches are very popular on YouTube, ${ }^{20}$ and therefore it is likely that YouTube users that were searching for ASMR at that site switched to searching for ASMR at Pornhub.

According to specialized literature (see Schmidt 1975; Both et al. 2004), sexual arousal (and the increase in sexual activity) after pornography viewing last for up to 24 hours, so our findings are compatible with pornography viewing being the channel behind the observed increase in rapes in the 22-hour period after the outage. Additionally, the results are in line with the observed fact that more than $50 \%$ of sex offenders consume pornography before committing a sexual assault (Marshall 1988).

Overall, we conclude that evidence only supports the mechanism of pornography viewing. In the following section we develop a simple model to rationalize our interpretation that pornography viewing increases rapes.

\section{Theoretical framework: pornography viewing and rapes}

We focus on the behavior of potential male sexual offenders. ${ }^{21}$ Our model has 2 stages. In the first stage, the agent decides how much pornography to consume subject to his time constraint. In the second stage, the agent decides whether or not to rape taking into account the costs and benefits associated to raping. Important to our setting

\footnotetext{
${ }^{19}$ ASMR is an experience or feeling triggered by specific auditory or visual stimuli, such as quiet and whispery noises, usually accompanied by feelings of relaxation and well-being.

${ }^{20}$ According to BBC news, there are over 13 million videos of people trying to trigger ASMR feeling on YouTube (https://www.bbc.com/news/av/newsbeat-45957504/asmr-i-can-make-your-brain-tingle).

${ }^{21}$ Since males are by far the predominant perpetrators of rapes as well as the biggest consumers of pornography (see, for example, Russell 1984), we are calling the offender a "he."
} 
is that in the first stage the agent is unable to predict perfectly his future behavior if he were sexually aroused in the second stage. The behavioral economics literature names this as the hot-cold empathy gap, a cognitive bias in which individuals underestimate the influences of visceral factors (such as sexual arousal) on their own future behavior (Loewenstein 2000).

Formally, sexual arousal of individual $i\left(v_{i}\right)$ depends on the consumption of pornography by individual $i, X_{i P}$. We assume that sexual arousal increases with the consumption of pornography, $v_{i}{ }^{\prime}\left(X_{i P}\right)>0$. An agent is in "hot" or "cold" mode depending on whether sexual arousal is above or below a personal threshold, $\overline{v_{l}}$. An agent is in hot mode if $v_{i}\left(X_{i P}\right) \geq \bar{v}_{l}$, and he is in cold mode if $v_{i}\left(X_{i P}\right)<\bar{v}_{l}$.

We assume that in the first stage, being in cold mode, the agent naively predicts that in the second stage his sexual arousal will always be below his personal threshold (i.e, that in the second stage he will always be in cold mode). Under this assumption, in the first stage the agent solves the following maximization problem, where $X_{i Y}$ is YouTube consumption, $X_{i o}$ is the consumption of all other leisure activities, and $L_{i}$ is leisure endowment $\left(X_{i P}, X_{i Y}, X_{i 0}\right.$, and $L_{i}$ are measured in hours):

$$
\max U\left(X_{i P} ; X_{i Y} ; X_{i O}\right) \text {, s.t. } X_{i P}+X_{i Y}+X_{i 0} \leq L_{i}, \text { for } i=1, \ldots, N \text {. }
$$

The agent solves this problem and chooses the optimal bundle of leisure consumption, including the optimal consumption of pornography $\left(X_{i P}^{*}\right) .^{22}$

In the second stage, the agent decides whether or not to rape conditional on the amount of pornography viewing chosen in the previous stage. According to the rational crime model (Becker 1968), the agent decides whether or not to rape by comparing the costs and benefits of raping. In our model, we follow the behavioral economics literature and we assume that being in hot mode affects both perceived

\footnotetext{
${ }^{22} \mathrm{We}$ assume local non-satiation so that the time constraint will hold with equality.
} 
costs and benefits of raping: it decreases the perceived cost of being caught (see Nagin 2008; Van Winden and Ash (2012) and increases the utility from raping (Loewenstein 2000). ${ }^{23}$

For simplicity, we normalize the utility of not raping at zero. Thus, the agent rapes if the utility from raping is greater than zero. Formally, the agent rapes if

$$
U(\text { Rape })=\alpha+\beta \mathbf{1}\left(v_{i}\left(X_{i P}^{*}\right) \geq \bar{v}_{l}\right)-\left(c-\delta \mathbf{1}\left(v_{i}\left(X_{i P}^{*}\right) \geq \bar{v}_{l}\right)\right)>0
$$

where $\mathbf{1}\left(v_{i}\left(X_{i P}^{*}\right) \geq \bar{v}_{l}\right)$ is an indicator that takes the value one if the agent is in hot mode, $\alpha, \beta$, and $\delta$ are parameters greater than zero, $c$ is the agent's expected cost of being caught (includes the probability of being caught and the length of the sentence), and $\left(c-\delta \mathbf{1}\left(v_{i}\left(X_{i P}^{*}\right) \geq \bar{v}_{l}\right)\right)$ is the agent's perceived cost of being caught. We assume $\alpha<c$ and $\alpha+\beta+\delta>c$.

In the cold mode, $v_{i}\left(X_{i P}^{*}\right)<\overline{v_{l}}$, and $U($ Rape $)=\alpha-c$. Since $\alpha<c$, in the cold mode the agent decides not to rape. In the hot mode the agent rapes since $v_{i}\left(X_{i P}^{*}\right) \geq$ $\overline{v_{l}}$, and $U($ Rape $)=\alpha+\beta-c+\delta>0$.

In terms of our model, YouTube outage implies an additional restriction to the optimization problem: $X_{i Y}=0$. This implies that, in equilibrium, some agents end up consuming more pornography, thus increasing the probability of being in hot mode.

To round off, YouTube outage decreases the opportunity cost of pornography viewing relative to alternative activities, thus potentially increasing the equilibrium level of pornography viewing. The increase in pornography viewing leads to some agents crossing their sexual arousal threshold. Those agents that cross the threshold end up raping.

\section{Final remarks}

\footnotetext{
${ }^{23}$ In general, visceral factors determine the trade-off between different goods and activities; thirst, for example, increases one's preference for water, and sexual arousal increases one's preference for having sex (Loewenstein 2000).
} 
YouTube experienced a major global interruption on October $16^{\text {th }}, 2018$. Using high-frequency crime data from the U.S., we document an increase in the number of rapes in the 24-hour period following the outage. We explore various competing mechanisms and we find support to the increase in rapes being driven by an increase in pornography viewing.

The association between the increase in pornography viewing and the increase in rapes can be rationalized by combining previous research in psychology and behavioral economics. Research in psychology indicates that an important fraction of male students in the U.S. (25 to 30 percent) admit to some likelihood of raping or forcing sex acts on a woman if they could get away with it (Malamuth 1984; Edwards, Bradshaw, and Hinsz 2014). The behavioral economics literature indicates that under the influence of visceral factors (such as being sexually aroused) individuals decide without fully taking into account the consequences of their acts. In a nutshell, our framework postulates that pornography viewing increases sexual arousal, which in turn increases the utility from raping and decreases the perceived cost of being caught, thus increasing the probability of raping. 


\section{References}

Abbey, Antonia, Tina Zawacki, Philip Buck, A. Monique Clinton, and Pam McAuslan (2001). "Alcohol and sexual assault." Alcohol Research \& Health, 25 (1), 43-51.

Allcott, Hunt, Luca Braghieri, Sarah Eichmeyer and Matthew Gentzkow (2019). "The welfare effects of social media." National Bureau of Economic Research, No. w25514.

Becker, Gary (1968). “Crime and punishment: An economic approach.” Journal of Political Economy 76, 169-217.

Bhuller, Manudeep, Tarjei Havnes, Edwin Leuven, and Magne Mogstad (2013). "Broadband Internet: an information superhighway to sex crime?" The Review of Economic Studies 80 (4), 1237-1266.

Both, Stephanie, Mark Spiering, Walter Everaerd, and Ellen Laan (2004). "Sexual behavior and responsiveness to sexual stimuli following laboratory-induced sexual arousal.” Journal of Sex Research 41 (3), 242-258.

Card, David and Gordon Dahl (2011). "Family violence and football: The effect of unexpected emotional cues on violent behavior." Quarterly Journal of Economics $126(1), 103-143$.

Cohn, Ellen (1993). "The prediction of police calls for service: The influence of weather and temporal variables on rape and domestic violence." Journal of Environmental Psychology 13 (1), 71-83.

DeFronzo, James (1984). "Climate and crime: tests of an FBI assumption." Environment and Behavior 16, 185-210.

DellaVigna, Stefano and Eliana La Ferrara (2015). "Economic and social impacts of the media." Handbook of Media Economics (1), 723-768. 
Edwards, Sarah, Kathryn Bradshaw, and Verlin Hinsz (2014). "Denying rape but dndorsing forceful intercourse: Exploring differences among responders." Violence and Gender 1 (4), 188-193.

Enikolopov, Ruben, Alexey Makarin, and María Petrova (2017). "Social media and protest participation: Evidence from Russia.” Available at SSRN 2696236.

Enikolopov, Ruben, María Petrova, and Konstantin Sonin (2018). "Social media and corruption.” American Economic Journal: Applied Economics 10 (1), 150-74.

Ferguson, Christopher and Richard Hartley (2009). "The pleasure is momentary...the expense damnable?: The influence of pornography on rape and sexual assault." Aggression and Violent Behavior 14 (5), 323-329.

Fisher, William and Guy Grenier (1994). "Violent pornography, antiwoman thoughts and antiwoman acts: In search of reliable effects.” Journal of Sex Research $31,23-38$.

Foubert, John (2017). "The public health harms of pornography: the brain, erectile dysfunction, and sexual violence." Dignity: A Journal on Sexual Exploitation and Violence (2) 3, Article 6.

Gavey, Nicola (2013). Just sex?: The cultural scaffolding of rape. Routledge.

Groth A. Nicholas (1979). Men who rape: the psychology of the offender. New York: Plenum.

Hald, Gert and Neil Malamuth (2015). "Experimental effects of exposure to pornography: The moderating effect of personality and mediating effect of sexual arousal.” Archives of Sexual Behavior 44 (1), 99-109.

Heß, Simon (2017). "Randomization inference with Stata: A guide and software.” The Stata Journal 17 (3), 630-651. 
Jensen, Robert (1995). "Pornography and the limits of experimental research." In Dines, G. and Humes, J. (eds.), Gender, Race, and Class in Media, 417-423.

Johnson, Scott (2006). Physical abusers and sexual offenders: Forensic and clinical strategies. CRC Press.

Koss, Mary, Thomas Dinero, Cynthia Seibel, and Susan Cox (1988). "Stranger and acquaintance rape: Are there differences in the victim's experience?." Psychology of Women Quarterly 12 (1), 1-24.

Lindo, Jason, Peter Siminski, and Isaac Swensen (2018). "College party culture and sexual assault.” American Economic Journal: Applied Economics 10 (1), 236-265.

Linz, Daniel, Edward Donnerstein, and Steven Penrod (1988). "Effects of longterm exposure to violent and sexually degrading depictions of women." Journal of Personality and Social Psychology 55, 758-768.

Loewenstein, George (2000). "Emotions in economic theory and economic behavior.” American Economic Review - Papers and Proceedings 90 (2), 426-432.

Malamuth, Neil (1984). “Aggression against women: Cultural and individual causes." In Malamuth, N. and Donnerstein, E. (eds.), Pornography and Sexual Aggression, Academic Press, New York.

Malamuth, Neil and Joseph Ceniti (1986). "Repeated exposure to violent and nonviolent pornography: Likelihood of raping ratings and laboratory aggression against women.” Aggressive Behavior 12, 129-137.

Malamuth, Neil, Tamara Addison, and Mary Koss (2000). "Pornography and sexual aggression: Are there reliable effects and can we understand them?" Annual Review of Sex Research 11 (1), 26-91. 
Marshall, William (1988). "Pornography and sex offenders." In Pornography: Research Advances \& Policy Considerations. Hillsdale (NJ): Lawrence Erlbaum, 185214.

Mosquera, Roberto, Mofioluwasademi Odunowo, Trent McNamara, Xiongfei Guo, and Ragan Petrie. "The economic effects of Facebook" (2019). Available at SSRN: 3312462.

Mould, Douglas (1988). "A critical analysis of resent research of violent erotica." Journal of Sex Research, 24, 326-340.

Munyo, Ignacio and Martín Rossi (2013). "Frustration, euphoria, and violent crime.” Journal of Economic Behavior \& Organization 89, 136-142.

Nagin, Daniel (1998). "Criminal deterrence research at the outset of the twentyfirst century." Crime and Justice 23, 1-42.

National Research Council (1996). Understanding violence against women. Washington, DC: The National Academies Press.

Newey, Whitney and Kenneth West (1994). "Automatic lag selection in covariance matrix estimation.” Review of Economic Studies 61 (4), 631-653.

Nolte, Andre (2019). "The internet effects on sex crime and murder - evidence from the broadband internet expansion in Germany." Journal of Economic Behavior \& Organization $165(\mathrm{C})$, 82-99.

Perry, Josephus and Miles Simpson (1987). "Violent crimes in a city: environmental determinants." Environment and Behavior 19, 77-90.

Russell, Diana (1984). Sexual exploitation: Rape, child sexual abuse, and workplace harassment (pp. 29-66). Beverly Hills, CA: Sage Publications. 
Schmidt, Gunter (1975). "Male-female differences in sexual arousal and behavior during and after exposure to sexually explicit stimuli." Archives of Sexual Behavior 4, 353-365.

Turvey, Brent (2013). Forensic victimology: Examining violent crime victims in investigative and legal contexts. Academic Press.

Van Winden, Frans and Elliott Ash (2012). "On the behavioral economics of crime.” Review of Law \& Economics 8 (1), 181-213.

Yang, Dong-ouk and Gahyun Youn (2012). "Effects of exposure to pornography on male aggressive behavioral tendencies." The Open Psychology Journal 5 (1). 
Table 1. Summary statistics of crime data

\begin{tabular}{ccccc}
\hline & Mean & $\begin{array}{c}\text { Standard } \\
\text { deviation }\end{array}$ & Minimum & Maximum \\
\hline Rapes & 6.54 & 3.21 & 0 & 21 \\
Criminal offenses & $1,976.49$ & 211.78 & 1,089 & 2,523 \\
Non-criminal offenses & $4,281.58$ & 477.96 & 2,232 & 6,088 \\
Alcohol offenses & 53.04 & 21.09 & 17 & 140 \\
Drug offenses & 187.49 & 25.72 & 66 & 260 \\
Other sexual offenses & 31.50 & 14.02 & 5 & 75 \\
Observations & 820 & & & \\
\hline
\end{tabular}

Notes: Table 1 reports summary statistics of "daily" data. Data was constructed using the date and time of the incident, and normalized so that all "days" start at the time of the outage (9pm Eastern time). Criminal offenses include theft (a category that includes theft from vehicle, theft of vehicle, property crime, robberies, and breaking \& entering) and assaults. Non-criminal offenses include traffic offenses, community policing, and disorder. 


\begin{tabular}{lccccc}
\hline & \multicolumn{5}{c}{ Dependent variable: Rapes } \\
& $(1)$ & $(2)$ & $(3)$ & $(4)$ & $(5)$ \\
YouTube outage & 4.47 & 4.41 & 4.16 & 4.36 & 3.62 \\
& $(0.11)^{* * *}$ & $(0.25)^{* * *}$ & $(0.40)^{* * *}$ & $(0.81)^{* * *}$ & $(0.77)^{* * *}$ \\
& $\{0.16\}^{* * *}$ & $\{0.25\}^{* * *}$ & $\{0.61\}^{* * *}$ & $\{0.95)^{* * *}$ & $\{0.84\}^{* * *}$ \\
& {$[0.09]$} & {$[0.08]$} & {$[0.09]$} & {$[0.13]$} & {$[0.15]$} \\
R-squared & & & & & \\
Day of the week & 0.002 & 0.094 & 0.105 & 0.187 & 0.260 \\
Month & No & Yes & Yes & Yes & Yes \\
Day of month & No & No & Yes & Yes & Yes \\
Time trend & No & No & No & Yes & Yes \\
Observations & No & No & No & No & Yes \\
& 820 & 820 & 820 & 820 & 820 \\
\hline
\end{tabular}

Notes: Table 2 uses daily data for the period January $1^{\text {st }}, 2017$ to March $31^{\text {st }}, 2019$. White-Huber robust standard errors are in parentheses. Newey-West heteroskedasticity- and autocorrelation-consistent standard errors are in braces. Pvalues obtained from randomized inference using the ritest command in Stata (500 replications) are in brackets. *Significant at the $10 \%$ level. $* *$ Significant at the $5 \%$ level. ***Significant at the $1 \%$ level. 


\begin{tabular}{lccc}
\hline & \multicolumn{3}{c}{ Dependent variable: Rapes } \\
& $(1)$ & $(2)$ & $(3)$ \\
YouTube outage & 2.97 & 2.92 & 4.00 \\
& $(0.69)^{* * *}$ & $(0.69)^{* * *}$ & $(0.95)^{* * *}$ \\
& $\{0.57\}^{* * *}$ & $\{0.64\}^{* * *}$ & $\{0.95\}^{* * *}$ \\
& {$[0.01]$} & {$[0.01]$} & {$[0.01]$} \\
Day of the week & Yes & Yes & Yes \\
Month & Yes & Yes & Yes \\
Time trend & Yes & Yes & Yes \\
Observations & 91 & 61 & 31 \\
& & & \\
\hline
\end{tabular}

Notes: Table 3 considers three symmetric periods around October $16^{\text {th }}, 2018$ : September $1^{\text {st }}$ to November $30^{\text {th }}$ (91 days), September $16^{\text {th }}$ to November $15^{\text {th }}$ (61 days), and October $1^{\text {st }}$ to October $31^{\text {st }}$ (31 days). White-Huber robust standard errors are in parentheses. Newey-West heteroskedasticity- and autocorrelation-consistent standard errors are in braces. P-values obtained from randomized inference using the ritest command in Stata (500 replications) are in brackets. *Significant at the $10 \%$ level. ** Significant at the $5 \%$ level. ***Significant at the $1 \%$ level. 


\begin{tabular}{|c|c|c|c|c|}
\hline & & Dependent & able: Rapes & \\
\hline & (1) & $(2)$ & $(3)^{1}$ & (4) \\
\hline YouTube outage & 4.41 & 5.00 & 7.60 & 6.98 \\
\hline & $(0.25)^{* * *}$ & $(0.55)^{* * *}$ & $(1.59) * * *$ & $(1.40)^{* * *}$ \\
\hline & {$[0.01]$} & {$[0.01]$} & {$[0.01]$} & {$[0.01]$} \\
\hline Month & No & Yes & Yes & Yes \\
\hline Day of month & No & No & Yes & Yes \\
\hline Time trend & No & No & No & Yes \\
\hline Observations & 117 & 117 & 117 & 117 \\
\hline $\begin{array}{l}\text { Notes: Table } 4 \mathrm{r} \\
\text { period starting or } \\
\text { March } 31^{\text {st }}, 2019 \\
\text { obtained from } \\
\text { replications) are } \\
\text { level. } * * * \text { Signific }\end{array}$ & $\begin{array}{l}\text { results obta } \\
\text { ays at } 9 \mathrm{pm} \\
\text { e-Huber rob } \\
\text { zed inferer } \\
\text { kets. *Signi } \\
\text { he } 1 \% \text { level. }\end{array}$ & $\begin{array}{l}\text { from restri } \\
\text { ern time, fo } \\
\text { tandard erı } \\
\text { sing the } \\
\text { at the } 10^{\circ}\end{array}$ & $\begin{array}{l}\text { e the samp } \\
\text { e period Ja1 } \\
\text { are in pare } \\
t \text { comman } \\
\text { vel. **Sign }\end{array}$ & $\begin{array}{l}\text { the } 24-\text { hour } \\
\text { y } 1^{\text {st }}, 2017 \text { to } \\
\text { ses. P-values } \\
\text { Stata }(500 \\
\text { ant at the } 5 \%\end{array}$ \\
\hline
\end{tabular}


Table 5. Robustness check: negative binomial specification

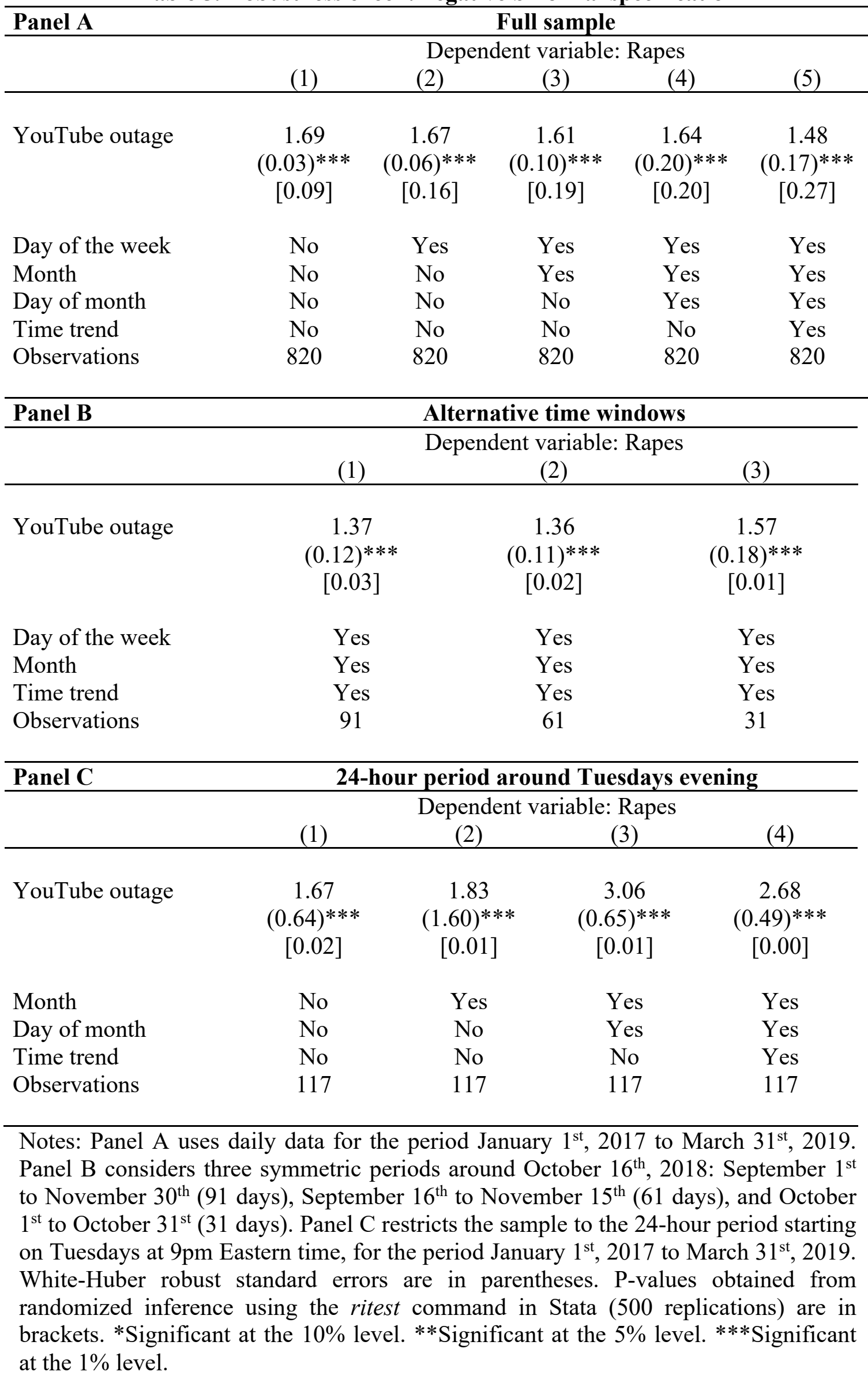


Table 6. Robustness check: panel structure

\begin{tabular}{|c|c|c|c|c|c|}
\hline & \multicolumn{5}{|c|}{ Dependent variable: Rapes } \\
\hline & $(1)$ & $(2)$ & $(3)$ & $(4)$ & $(5)$ \\
\hline YouTube outage & $\begin{array}{c}0.017 * * * \\
(0.001)\end{array}$ & $\begin{array}{c}0.014 * * * \\
(0.002)\end{array}$ & $\begin{array}{c}0.014 * * \\
(0.007)\end{array}$ & $\begin{array}{c}0.014 * * * \\
(0.005)\end{array}$ & $\begin{array}{c}0.013 \\
(0.012)\end{array}$ \\
\hline Police-station FE & Yes & Yes & Yes & Yes & Yes \\
\hline Police-station trend & No & Yes & Yes & Yes & Yes \\
\hline Day of the week & No & No & Yes & Yes & Yes \\
\hline Weather controls & No & No & No & Yes & Yes \\
\hline Month & No & No & No & No & Yes \\
\hline Police stations & 295 & 295 & 295 & 295 & 295 \\
\hline Observations & 241,900 & 241,900 & 241,900 & 241,900 & 241,900 \\
\hline
\end{tabular}




\begin{tabular}{|c|c|c|c|c|c|}
\hline & $\begin{array}{c}\text { (1) } \\
\text { Criminal } \\
\text { offenses }\end{array}$ & $\begin{array}{c}\text { (2) } \\
\text { Non- } \\
\text { criminal } \\
\text { offenses }\end{array}$ & $\begin{array}{c}\text { (3) } \\
\text { Other } \\
\text { sexual } \\
\text { offenses } \\
\end{array}$ & $\begin{array}{c}\text { (4) } \\
\text { Drug } \\
\text { offenses }\end{array}$ & $\begin{array}{c}\text { (5) } \\
\text { Alcohol } \\
\text { offenses }\end{array}$ \\
\hline YouTube outage & $\begin{array}{c}-45.21 \\
(35.11) \\
\{35.60\} \\
{[0.51]}\end{array}$ & $\begin{array}{c}-83.70 \\
(75.87) \\
\{73.06\} \\
{[0.55]}\end{array}$ & $\begin{array}{l}-3.16 \\
(3.15) \\
\{4.06\} \\
{[0.99]}\end{array}$ & $\begin{array}{c}3.21 \\
(5.48) \\
\{5.50\} \\
{[0.60]}\end{array}$ & $\begin{array}{c}-18.64 \\
(2.63)^{* * *} \\
\{2.49\} * * * \\
{[0.08]}\end{array}$ \\
\hline $\begin{array}{l}\text { Day of the week } \\
\text { Month } \\
\text { Day of month } \\
\text { Time trend } \\
\text { Observations }\end{array}$ & $\begin{array}{l}\text { Yes } \\
\text { Yes } \\
\text { Yes } \\
\text { Yes } \\
820\end{array}$ & $\begin{array}{l}\text { Yes } \\
\text { Yes } \\
\text { Yes } \\
\text { Yes } \\
820\end{array}$ & $\begin{array}{l}\text { Yes } \\
\text { Yes } \\
\text { Yes } \\
\text { Yes } \\
820\end{array}$ & $\begin{array}{l}\text { Yes } \\
\text { Yes } \\
\text { Yes } \\
\text { Yes } \\
820\end{array}$ & $\begin{array}{l}\text { Yes } \\
\text { Yes } \\
\text { Yes } \\
\text { Yes } \\
820\end{array}$ \\
\hline \multicolumn{6}{|c|}{$\begin{array}{l}\text { Notes: Criminal offenses include theft (a category that includes theft from vehicle, } \\
\text { theft of vehicle, property crime, robberies, and breaking \& entering) and assaults. } \\
\text { Non-criminal offenses include traffic offenses, community policing, and disorder. } \\
\text { White-Huber robust standard errors are in parentheses. Newey-West } \\
\text { heteroskedasticity- and autocorrelation-consistent standard errors are in braces. P- } \\
\text { values obtained from randomized inference using the ritest command in Stata }(500 \\
\text { replications) are in brackets. } * \text { Significant at the } 10 \% \text { level. } * * \text { Significant at the } 5 \% \\
\text { level. ***Significant at the } 1 \% \text { level. }\end{array}$} \\
\hline
\end{tabular}




\begin{tabular}{|c|c|c|c|c|c|c|}
\hline & & & ependen & iable: Rape & & \\
\hline & $(1)$ & $(2)$ & (3) & (4) & $(5)$ & $(6)$ \\
\hline During outage & -0.27 & -0.27 & -0.27 & -0.28 & -0.29 & -0.32 \\
\hline & $(0.00)^{* * *}$ & $(0.01)^{* * *}$ & $(0.02)^{* * *}$ & $(0.02)^{* * *}$ & $(0.03)^{* * *}$ & $(0.03)^{* * *}$ \\
\hline & $\{0.00\} * * *$ & $\{0.01\}^{* * *}$ & $\{0.02\} * * *$ & $\{0.02\} * * *$ & $\{0.03\} * * *$ & $\{0.03\}^{* * *}$ \\
\hline After outage & 0.23 & 0.23 & 0.23 & 0.21 & 0.22 & 0.19 \\
\hline & $(0.18)$ & $(0.15)$ & $(0.15)$ & $(0.16)$ & $(0.16)$ & $(0.16)$ \\
\hline & $\{0.10\}^{* *}$ & $\{0.10\} * *$ & $\{0.10\}^{* *}$ & $\{0.10\}^{* *}$ & $\{0.10\}^{* *}$ & $\{0.10\}^{*}$ \\
\hline Hour of the day & No & Yes & Yes & Yes & Yes & Yes \\
\hline Day of the week & No & No & Yes & Yes & Yes & Yes \\
\hline Month & No & No & No & Yes & Yes & Yes \\
\hline Day of the month & No & No & No & No & Yes & Yes \\
\hline Time trend & No & No & No & No & No & Yes \\
\hline Observations & 19,680 & 19,680 & 19,680 & 19,680 & 19,680 & 19,680 \\
\hline $\begin{array}{l}\text { Notes: Table } 7 \text { us } \\
\text { During outage is } \\
\text { Eastern time on Ty } \\
\text { 22-hour period sta } \\
\text { an hourly averag } \\
\text { Newey-West heter } \\
\text { * Significant at the }\end{array}$ & $\begin{array}{l}\text { s hourly dat } \\
\text { dummy val } \\
\text { esday } 16^{\text {th }}, 2 \\
\text { ting at } 11 \mathrm{pr} \\
\text { equal to } 0 \\
\text { oskedasticity } \\
10 \% \text { level. * }\end{array}$ & $\begin{array}{l}\text { a dataset fo } \\
\text { iable that t } \\
018 \text {. After } \\
\text { Eastern ti } \\
27 \text {. White- } \\
\text { - and auto } \\
\text { * Significan }\end{array}$ & $\begin{array}{l}\text { he period } \\
\text { es value } 1 \\
\text { age is a d } \\
\text { on Tues } \\
\text { aber robu } \\
\text { relation-c }\end{array}$ & $\begin{array}{l}\text { muary } 1^{\text {st }} \text {, } \\
\text { the } 2-\text { ho } \\
\text { my varia } \\
16^{\text {th }}, 20 \\
\text { standard } \\
\text { istent sta }\end{array}$ & $\begin{array}{l}017 \text { to Marc } \\
\text { period } 9 \mathrm{pm} \\
\text { that takes } \\
\text { The variab } \\
\text { rors are in } \\
\text { dard errors }\end{array}$ & $\begin{array}{l}\text { h } 31^{\text {st }}, 2019 . \\
\text { to } 10.59 \mathrm{pm} \\
\text { ralue } 1 \text { in the } \\
\text { le Rapes has } \\
\text { parentheses. } \\
\text { re in braces. } \\
1 \text { o }\end{array}$ \\
\hline
\end{tabular}


Figure 1. YouTube outages, by day

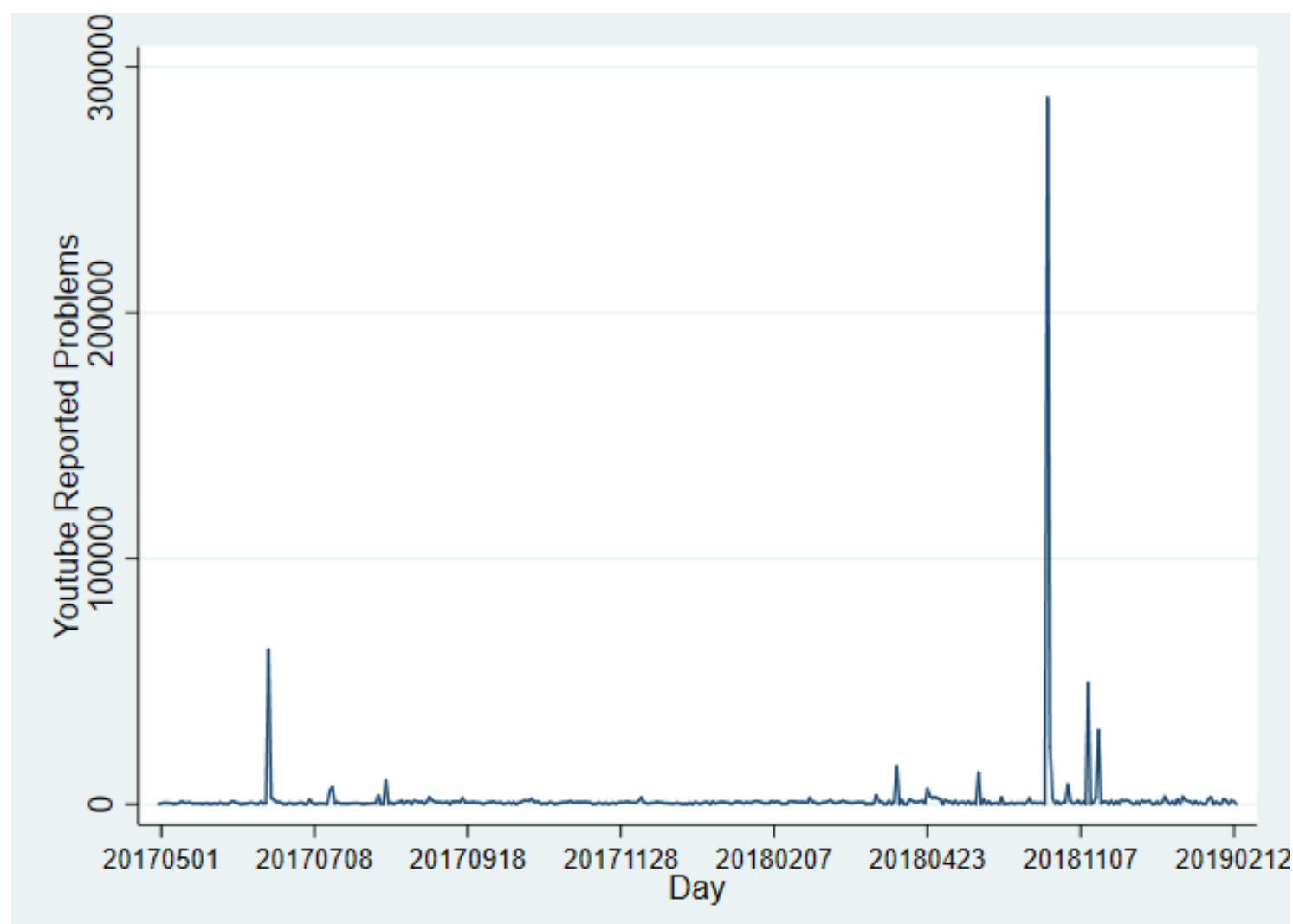

Source: Own elaboration, based upon data obtained from Downdetector. Downloaded on April 21 ${ }^{\text {st }}, 2019$. 
Figure 2. Distribution of rapes: all "Tuesdays" in the sample

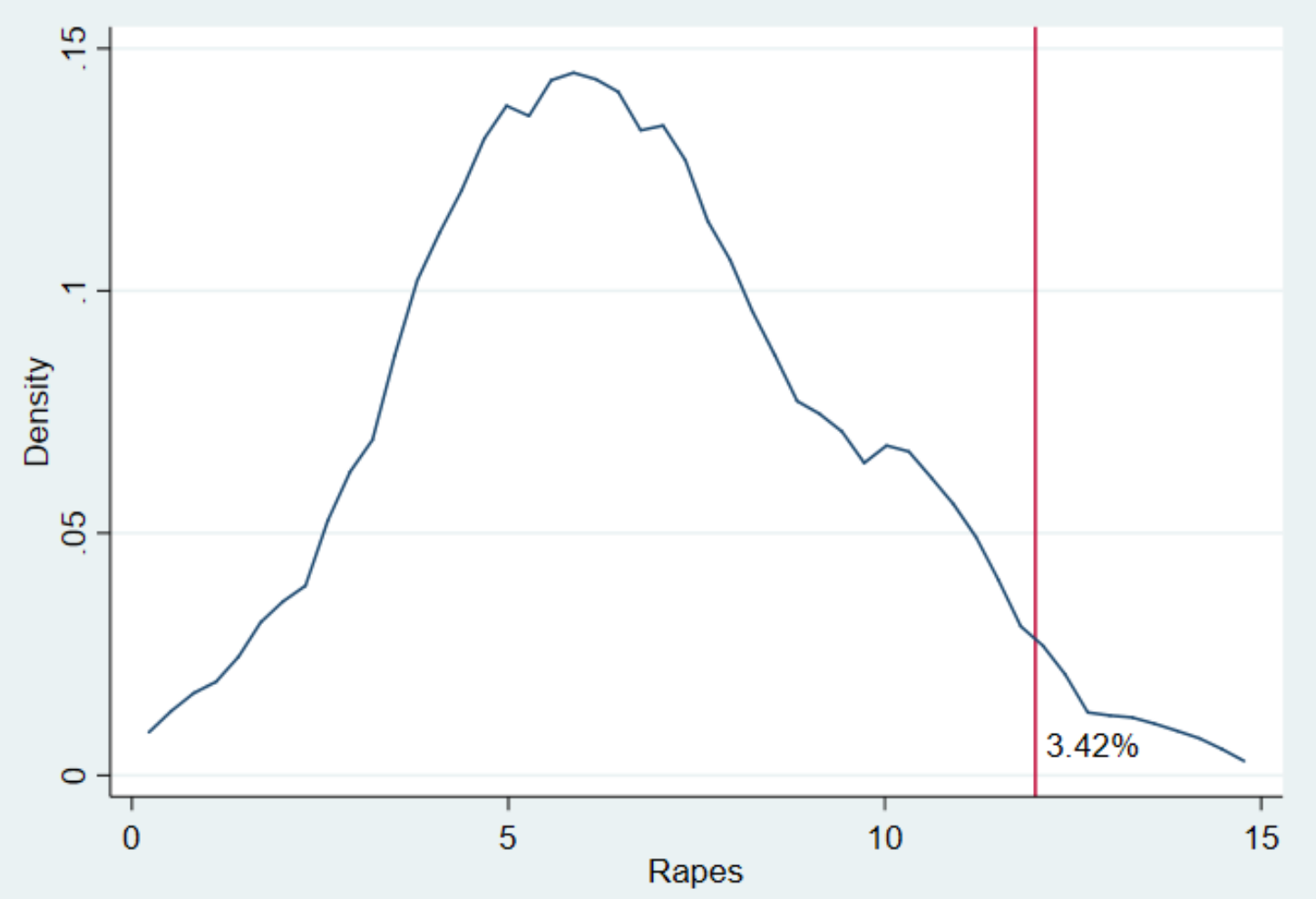

Note: $3.42 \%$ is the percentage of Tuesdays with more rapes than on Oct. 16 th, 2018 
Figure 3. Hourly distribution of rapes during and after the outage

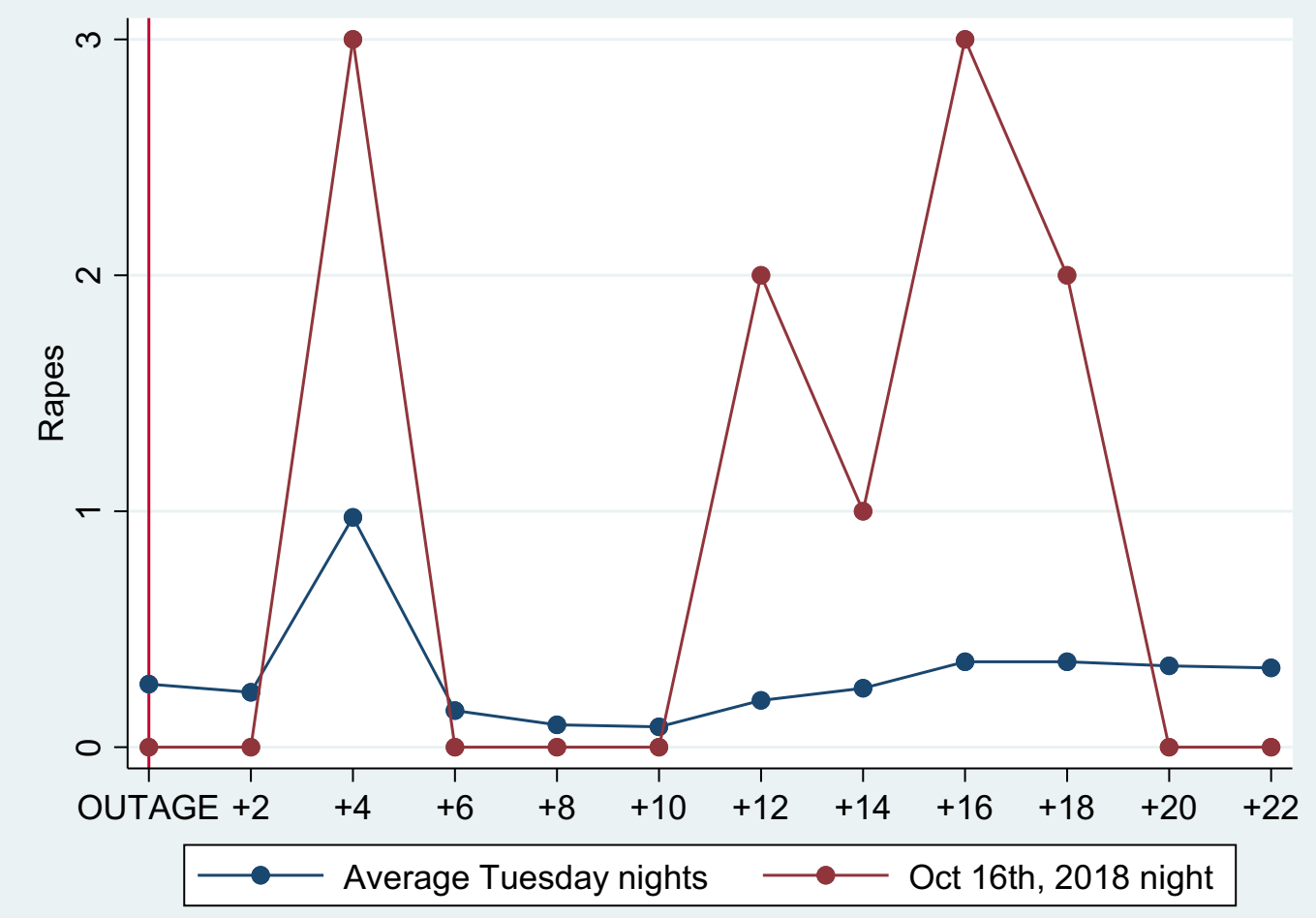


Figure 4. YouTube outage and the increase in Pornhub's traffic

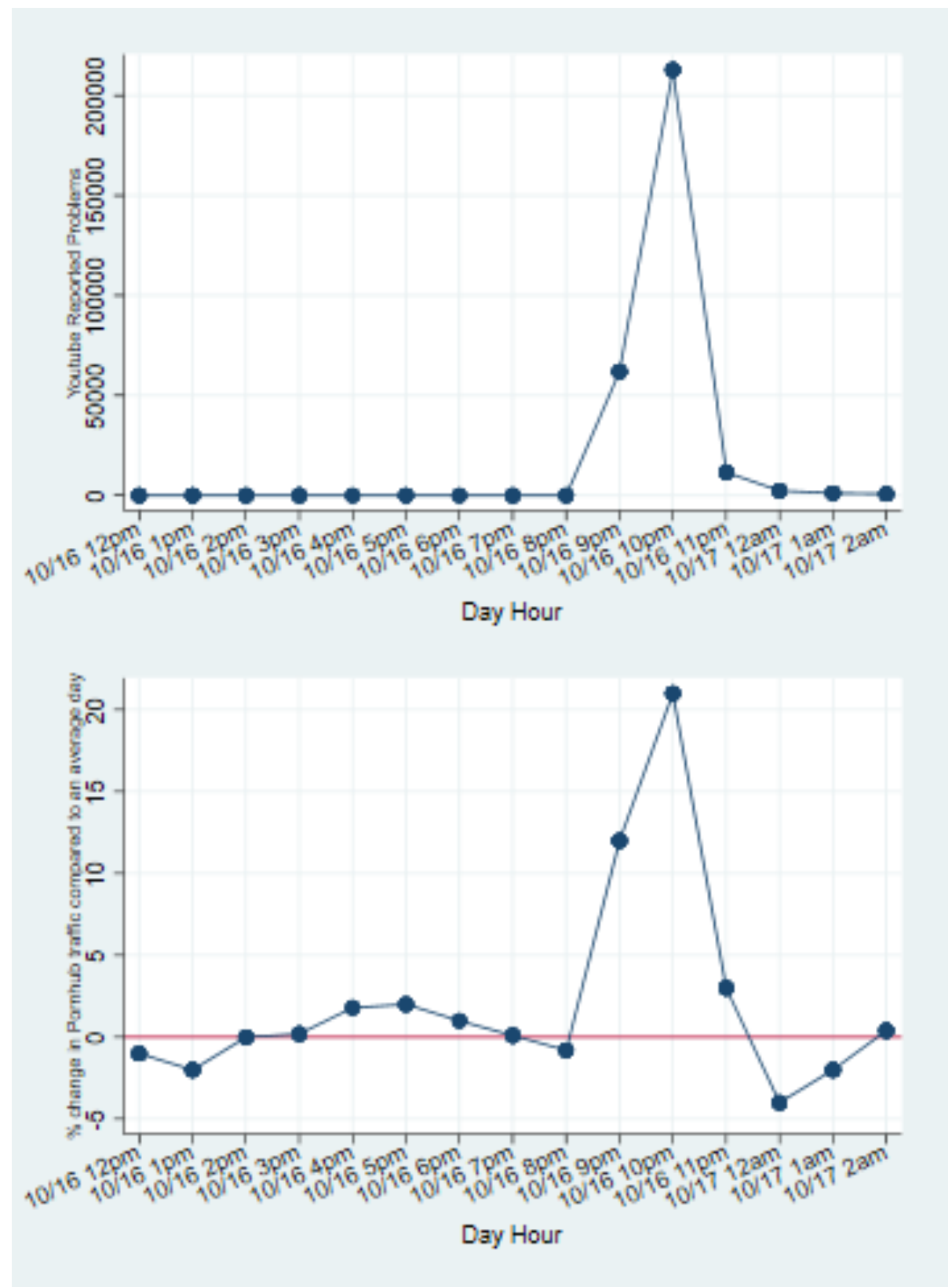

Source: Own elaboration, based upon data obtained from Downdetector and Pornhub (www.pornhub.com/insights/youtube-outage). Downloaded on December 22 $2^{\text {nd }}, 2018$. 